\title{
Passenger Demand Forecasting In Scheduled Transportation
}

\author{
Nilabhra Banerjee ${ }^{\mathrm{a}, *}$, Alec Morton ${ }^{\mathrm{a}}$, Kerem Akartunalı ${ }^{\mathrm{a}}$ \\ ${ }^{a}$ Department of Management Science, University of Strathclyde, Glasgow G4 OGE, UK
}

\begin{abstract}
The aim of this review article is to provide a synoptic and critical evaluation of the extensive research that has been performed in demand forecasting in the scheduled passenger transportation industry, specifically in the last few decades. The review begins with an attempt to classify and tabulate the research according to the properties of proposed models, their objectives and application areas in industry in different stages of the planning cycle. This is followed by an assessment of forecast methodologies with suggestions on different methodologies that industry practitioners can adopt to suit their specific needs and recommendations towards future directions of research. We also provide a look into the cross cutting concerns that need to be addressed by all forecasting systems irrespective of the domain or planning stage, such as demand unconstraining, aggregation and the role of expert judgement to incorporate the effect of other extraneous factors that might affect the demand. We conclude from our study that there is a lack of standardization in the way in which methods are described and tested. As a result, there is a lack of cumulative knowledge building. To redress this concern, we propose open source testbeds to facilitate benchmarking of new models. We also propose a checklist as a guideline to standardize the research reports and suggest that when proposing newer models, researchers may consider including a comparative study with existing standard models in research report.
\end{abstract}

Keywords: Demand Forecasting, Transportation, Seat Inventory

\footnotetext{
${ }^{*}$ Corresponding author

Email addresses: nilabhra.banerjee@strath.ac.uk (Nilabhra Banerjee), alec.morton@strath.ac.uk (Alec Morton), kerem.akartunali@strath.ac.uk (Kerem Akartunalı)
} 
Management, Strategic Planning, Budget Planning, Capacity Planning, Airlines, Bus, Railways

\section{Introduction}

Demand forecasting is an intrinsic component of business and commerce. The future is always uncertain and every business needs to predict the market as accurately as possible both for short term and strategic planning in order to see itself in a profitable position. In the passenger transport industry, our scope of discussion, business is very dependent on passenger demand because the items on sale here are perishable commodities. Right from designing route networks, arranging for vehicles with proper seat capacity for a network route to pricing the inventory for each vehicle in a route, every operation in every planning horizon depends on estimation of the demand. Passenger transportation occupies a major share in global business and therefore, passenger demand forecasting is a key subject of research. In 2017, airline industry alone grossed over 750 billion dollars catering to more than 4 billion passengers (IATA annual review, 2018). Passenger railway transportation is also a major industry, especially in Europe, USA, China and India. Majority of the forecasting research motivations arise from these two transportation sectors. However, we also consider niche transportation industries, such as intercity bus transport and cruise industry, as these industries also employ demand forecasting in their business planning.

We define scheduled transport as a routine vehicle movement between two or more points at pre-scheduled times, transporting passengers and/or cargo. Scheduled transport may be airline flights, ferries between two ports or intercity bus or rail transport. In scheduled passenger transport, forecasting has many applications. Forecasts can be "macro", predicting overall sales and help the strategic planning. Digging deeper, "micro" forecasting provides more granular predictions, on a day to day or even hour to hour basis. Fig. 1 show the applications that use forecasting tools to predict demand at different planning horizons. This figure, a slightly modified version of Wickham (1995)'s representation, is not a binding definition but is given to provide an idea on how forecasts are used at different levels of planning.

The departure date of a scheduled transport journey is often termed "day zero". It is the date when the vehicle leaves the origin point and begins its journey towards the destination. However, one year prior to the day zero, 


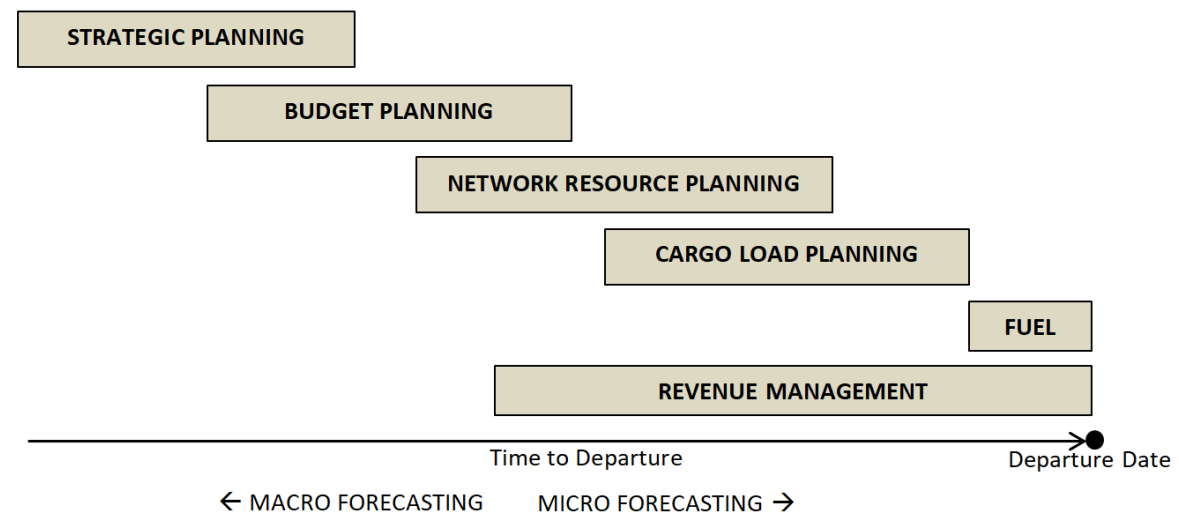

Figure 1: Application of forecasting in a timeframe prior to date of departure

it may not make sense to model individual departures on particular vehicles or trips. Rather, the total volume of passengers carried by certain groups of scheduled journeys is a more appropriate focus for forecasting. Strategic planning, as one can see from the Fig. 1, investigates a horizon more than a year ahead. This planning on the macro level provides projections to address probable business expansion issues such as increasing vehicle capacities or terminus passenger holding capacities, or adding new routes to the existing network. Another macro forecast based activity, budget planning, or income and expenditure planning, takes place yearly, semi yearly and even quarterly and often works on monthly projections.

Network resource planning requires a more granular level of forecasting and works to optimize the resource allocation across the network depending on passenger loads on each area of the network. This is a tricky problem, as resources need to be carefully allocated according to the demand on each route. Part of network resource planning is the crew assignment problem, which is complicated further by the fact that a bigger vehicle needs more experienced crews and additional cabin crews, which often becomes the case when the increased demand forces vehicle reallocation.

A passenger seat on a certain scheduled journey should be considered as a perishable commodity. If a seat remains unallocated (unsold), there is an opportunity missed to sell, which is not recoverable. On the other hand, if it is sold at a lower rate than what a customer is willing to pay, some profit is lost. Revenue management takes into cognizance these facts and tries to 
maximize the profit by dynamically pricing the seats in accordance with the demand. Revenue management starts as soon as the tickets for a scheduled journey are open for purchase and ends at the close of the sale before the departure. The sale of tickets does not end even if all the available seats are exhausted. Companies often "overbook" with an expectation that a certain number of passengers will fail to show up ("no show") at scheduled departure time. Overbooking is accomplished by using forecast figures of no show cases.

Several other processes that depend on passenger demand forecasts are cargo load planning, fuel load and in many long haul journeys, catering meal plans. The airline industry was first to adopt forecasting as an OR tool but before 1970s it was mainly for strategic planning. With the emergence of revenue management in 1970s, interest in forecasting increased. The 1980s and the 1990s saw a boom in revenue management research subsequent to the Airline Deregulation Act in the USA. The success of revenue management in the airline industry prompted other industries that deal with perishable commodities to adopt similar techniques. As earlier mentioned, passenger demand forecasting being central to the revenue management process, efforts to attain better forecasting techniques increased with the adoption of revenue management. From the 1990s onward, forecasting techniques were being implemented in various transportation industries like high speed rail, ferries and even in related disciplines such as predicting passenger volume in railway stations or airport terminals or determining cargo volume for air or surface freighters.

Forecasting models range from simple exponential smoothing to complex hierarchical models, and advances in computer science in last the two decades have helped to build complex models. Simulation of a forecasting model or comparing between model performances are quicker and easier with today's computation power. However forecasting is not a one step process. A lot of activity goes into data pre-processing. For example, a key activity is datastructuring for booking curves in order to produce day to day micro forecasts. Data unconstraining from censored data is another key pre-processing activity along with data aggregation. Results processing using forecast evaluation tools is also an important step. Often forecast evaluation tools are used to compare the models against benchmark models. In a comparative study, multiple models are evaluated. Some research combines forecasts from two different models to produce a hybrid forecast data.

The classification tree in Fig. 2 shows all the research activities that our review plans to investigate. Categorization rules of these models are given 


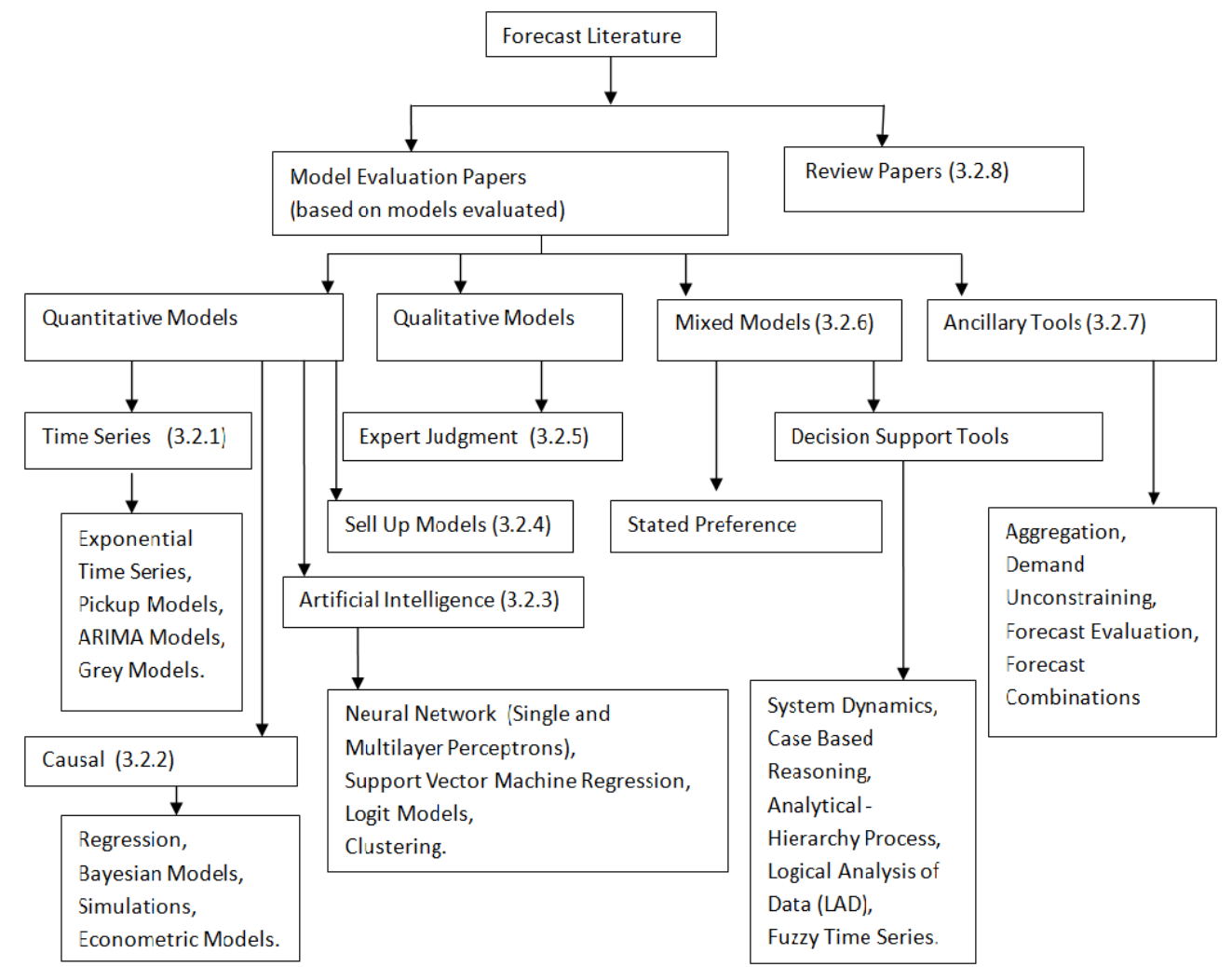

Figure 2: Classification of forecasting methods. Article chapters are mentioned where applicable

below.

- Quantitative models are models that emphasize on statistical analysis of data. They can be further categorized as follows.

- Time series models are those models which forecast from existing historical data.

- Causal models are used to estimate a relationship function between explanatory variables and the demand that needs to be forecasted.

- Artificial intelligence or machine learning tools are computer aided self-learning models that adjust to an optimal forecasting model 
by working through a set of historical data (training set) iteratively.

- Sell up forecast models are algorithms that specifically suit the revenue management models of low cost carriers.

- Qualitative models are models with which draw on human knowledge of judgement.

- Mixed models have features of both quantitative and qualitative modelling, for example, data collection through customer surveys followed by mathematical data analysis.

- Ancillary tools are models that are not forecast tools by themselves but often used in tandem with a forecast model to pre-process or analyze data or assimilate end results.

We will discuss our methodology to select the research papers for this review in the next section which will be followed by sections that review different aspects of forecasting including a very high level introduction to the models used and their applications. We then discuss the usage of the forecasting models in different industries and finally end with critical suggestions for improvement.

\section{Methodology}

Though there is no strict definition on how a literature review should be carried out, we followed the suggestions by (Avni et al., 2015) and (Wee and Banister, 2016). These are well cited articles that have discussed the currently adopted research review methodologies in detail. We also drew inspiration from two seminal literature reviews on forecasting by (Wickham, 1995) and (Fildes et al., 2008). The methodology is discussed briefly next, with the flowchart in Fig. 3 presenting an overview of the process.

\subsection{Topic}

Topic underlines the scope of the review. Generally, a topic search engine defines topic as a set of key phrases in title, abstract and keyword lists. However, definition of topic also includes the research areas, subject matter categories of the search interest. The topic is visualised through building the search criterion, which lists the keywords and defines rules to include and 


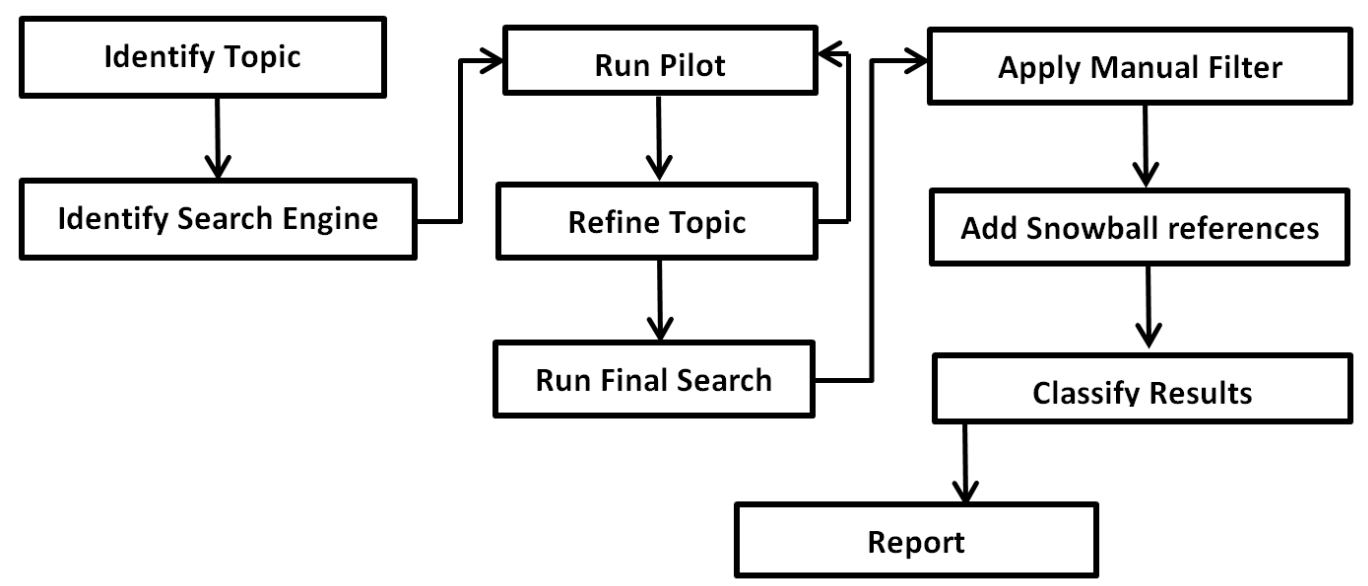

Figure 3: Forecasting methodology: process flowchart

exclude research areas. Topic identification and building the search criterion is generally an iterative process. Fig. 3 shows that we had to run the step 3 and step 4 several times to define the search rules. Final search criterion is presented in Appendix B (section 5.2). Although our targeted search time span was 1987-2017, we also referred to few pioneering works before 1987 in our study.

\subsection{Search Engine}

Between the alternatives, Web of Science and Google Scholar, we decided to choose Web of Science (WOS). While Google Scholar is equally well stocked as WOS, WOS is restricted to peer reviewed research papers and so allows for greater quality control. We also noted that the WOS advanced search option have more filtering abilities than Google Scholar to narrow down the search into a manageable size.

\subsection{Manual Filtering}

Given the search approach, 1,392 results were returned. We filtered out research papers from allied fields such as network resource optimisation or revenue management manually on a case by case basis.

\subsection{Snowballing}

Forward snowballing is a method of selecting the articles that have cited a given article while backward snowballing is selecting articles that a given 
article has cited. We have used both of these techniques on our list of articles to include some well cited papers, which were otherwise not listed in our WOS search results.

The final list of literature that are reviewed consists of 120 titles, which includes book sections, journal articles, theses and conference papers. We applied the stratified selection approach (Wee and Banister, 2016) to cite selected articles in our paper as case examples and those titles, which are not cited as case examples in this article, are included in the list uploaded as a supplementary resource.

\subsection{Classification Method}

For our discussion, we grouped the research papers according to the classification as shown in Fig. 2. Section 3.1.1 provides a report followed by discussions in Section 3.2

\section{Discussion}

\subsection{Classification Report}

\subsubsection{Classification based on Methodologies used}

Table 1 is the list of research papers, according to the classification. We remark to the reader that papers comparing models belonging to different classes are listed multiple times, which is why the number of instances in the classification results is higher than the total number of papers.

Comparative studies are also charted to get a glimpse of how the common models performed when pitted against each other. In Table 2, the best performing model for each research paper is marked with $\mathrm{W}$ (winner) while other models in the fray are marked with L (loser). The ties are marked with $\mathrm{T}$. The rightmost column provides information on the dataset on which the analysis was done. About the datasets, it is worth noting how varied they are, ranging from Box Jenkins data of 1970s to a recent Turkish airline dataset.

As with comparative studies, there are hybrid models as well which are combinations of multiple models. This combinations may be simple linear combinations, non linear combinations or complex models like ANFIS. We tend not to further subdivide this category for the sake of brevity. However we prefer to choose the phrase hybrid model instead of combinatorial model as it makes better classification of this category. A hybrid model may behave completely differently from the base models when combined together, and 
Table 1: List of Researches by Forecasting Methods (Note: Comparative study papers counted multiple times)

\begin{tabular}{|c|c|c|c|}
\hline \multirow[t]{19}{*}{ Quantitative } & \multicolumn{2}{|l|}{ Time Series Methods } & 38 \\
\hline & ARIMA & 18 & \\
\hline & ETS & 6 & \\
\hline & Pickup & 7 & \\
\hline & Grey System Models & 4 & \\
\hline & GARCH & 3 & \\
\hline & Artificial Intelligence Methods & & 25 \\
\hline & Neural Network & 18 & \\
\hline & SVM & 6 & \\
\hline & Clustering & 1 & \\
\hline & Causal Methods & & 45 \\
\hline & Regression & 16 & \\
\hline & Logit & 11 & \\
\hline & Econometric Models & 7 & \\
\hline & Kalman Filter & 5 & \\
\hline & Stochastic Distribution Models & 3 & \\
\hline & Other Causals & 3 & \\
\hline & Sell Up Methods & & 2 \\
\hline & Q Forecasting and Fare Adjustment & 2 & \\
\hline \multirow[t]{2}{*}{ Qualitative } & Qualitative Methods & & 2 \\
\hline & Expert Judgment & 2 & \\
\hline \multirow[t]{4}{*}{ Mixed } & Stated Preference & & 3 \\
\hline & Decision Support Tools & & 7 \\
\hline & System Dynamics & 2 & \\
\hline & Other DSS Tools & 5 & \\
\hline \multirow[t]{4}{*}{ Ancillary Tools } & Ancillary Tools & & 17 \\
\hline & Demand Unconstraining & 3 & \\
\hline & Forecast Combinations & 12 & \\
\hline & Forecast Measurements & 2 & \\
\hline Review Papers & Review Papers & & 4 \\
\hline
\end{tabular}


Table 2: Tabular listing of comparative study papers

\begin{tabular}{|c|c|c|c|c|c|c|c|c|c|c|}
\hline References & ETS & Regr & Pickup & $\mathrm{AR}$ & ARMA & ARIMA & $\mathrm{NN}$ & SVM & Kalman & Datasource \\
\hline Wickham (1995) & $\mathrm{L}$ & $\mathrm{L}$ & $\mathrm{W}$ & & & & & & & $\begin{array}{l}\text { A major North } \\
\text { American air- } \\
\text { line }\end{array}$ \\
\hline Zickus (1998) & & W & $\mathrm{L}$ & & & & & & & $\begin{array}{l}\text { PODS simula- } \\
\text { tor }\end{array}$ \\
\hline Faraway and Chatfield (1998) & & & & & & $\mathrm{T}$ & $\mathrm{T}$ & & & $\begin{array}{l}\text { Box Jenkins } \\
\text { airline data. }\end{array}$ \\
\hline Yang and Wang (2002) & & & & $\mathrm{L}$ & $\mathrm{L}$ & $\mathrm{L}$ & $\mathrm{W}$ & & & A Bus Line \\
\hline Riedel and Gabrys (2003) & W & $\mathrm{L}$ & & $\mathrm{L}$ & $\mathrm{L}$ & & & & & $\begin{array}{l}\text { Lufthansa Air- } \\
\text { line }\end{array}$ \\
\hline Profillidis and Botzoris (2007) & & W & & $\mathrm{L}$ & $\mathrm{L}$ & & & & & Greek Railway \\
\hline Samagaio and Wolters (2010) & $\mathrm{L}$ & & & & & W & & & & $\begin{array}{l}\text { Lisbon Airport } \\
\text { government } \\
\text { data }\end{array}$ \\
\hline Xie et al. (2013) & & & & & & $\mathrm{L}$ & $\mathrm{L}$ & W & & $\begin{array}{l}\text { CEIC } \\
\text { Database. } \\
\text { Hongkong } \\
\text { Airport data }\end{array}$ \\
\hline Milenkovic et al. (2014) & & & & & & $\mathrm{L}$ & $\mathrm{L}$ & & W & $\begin{array}{ll}\begin{array}{l}\text { Serbian } \\
\text { way }\end{array} & \text { Rail- } \\
\end{array}$ \\
\hline Srisaeng et al. (2015) & & $\mathrm{L}$ & & & & & $\mathrm{W}$ & & & $\begin{array}{l}\text { Australian do- } \\
\text { mestic carrier }\end{array}$ \\
\hline Ghomi and Forghani (2016) & & & & & & W & $\mathrm{L}$ & & & $\begin{array}{l}\text { A major Turk- } \\
\text { ish airline }\end{array}$ \\
\hline
\end{tabular}

therefore should be treated as a modelling tool on its own. We have listed the hybrid models as well as in Table 3. The papers report that hybrid models performed better than base models working individually. Hybridization by linear combination is quite common since Bates and Granger (1969). We can however find in our list the usage of newer non linear techniques like variance based pooling, adaptive network based fuzzy inference system (ANFIS) and others.

\subsubsection{Classification based on Planning Horizon}

Table 4 is the breakdown of research papers on planning horizons, whether they are strategic long term planning or tactical planning for near short term effects or on day to day operational aspects. Strategic planning is related with infrastructure development such as terminal capacity or purchase of vehicles. Economic growth estimation to understand ridership in a geographical region is also an aspect of strategic planning. Tactical planning is related to vehicle reassignment across the network according to passenger demand. In short 
Table 3: Hybrid Models

\begin{tabular}{|c|c|c|}
\hline References & $\begin{array}{l}\text { Base Forecasting Tech- } \\
\text { niques }\end{array}$ & $\begin{array}{l}\text { Hybridisation Tech- } \\
\text { nique }\end{array}$ \\
\hline $\begin{array}{l}\text { Riedel and Gabrys } \\
(2005)\end{array}$ & $\begin{array}{l}\text { Evaluation of different } \\
\text { linear and nonlinear } \\
\text { forecast combinations }\end{array}$ & $\begin{array}{l}\text { Linear Combinations, } \\
\text { Sigmoid function } \\
\text { based combination, } \\
\text { non linear neuro fuzzy } \\
\text { combination (AN- } \\
\text { FIS). Hierarchical } \\
\text { combinations. }\end{array}$ \\
\hline Lemke et al. (2009) & $\begin{array}{l}\text { Single ETS, Brown, } \\
\text { Regression, Forecast } \\
\text { Combinations }\end{array}$ & $\begin{array}{l}\text { Linear Combinations, } \\
\text { Variance based Pool- } \\
\text { ing. }\end{array}$ \\
\hline Carson et al. (2011) & $\begin{array}{l}\text { Logit and multiple re- } \\
\text { gression }\end{array}$ & $\begin{array}{l}\text { Composite Economet- } \\
\text { ric Model (Aggregat- } \\
\text { ing Individual market) }\end{array}$ \\
\hline Wang et al. (2013) & $\begin{array}{l}\text { Elastic Coefficient, } \\
\text { Grey Model }\end{array}$ & Weighted Combination \\
\hline Ma et al. (2014b) & $\begin{array}{l}\text { Time Series Models } \\
\text { (ARIMA) }\end{array}$ & $\begin{array}{lr}\text { Interactive } & \text { Multiple } \\
\text { Model-based } & \text { Pattern } \\
\text { Hybrid } & \\
\end{array}$ \\
\hline $\begin{array}{l}\text { Jiang and Miglionico } \\
\text { (2014) }\end{array}$ & $\begin{array}{l}\text { Ensemble Empirical } \\
\text { Mode Decomposition, } \\
\text { Grey Model }\end{array}$ & $\begin{array}{l}\text { Multistep Hybridiza- } \\
\text { tion Technique with } \\
\text { optimization by } \\
\text { SVM parallel particle } \\
\text { swarm. }\end{array}$ \\
\hline Zong (2015) & $\begin{array}{l}\text { Grey Model,Neural } \\
\text { Network }\end{array}$ & $\begin{array}{l}\text { A quadratic regression } \\
\text { equation. }\end{array}$ \\
\hline Leng et al. (2015) & $\begin{array}{l}\text { Logit, Gravity, In- } \\
\text { duced demand formu- } \\
\text { lation }\end{array}$ & Composite Model \\
\hline Nieto $(2015)$ & ARIMA & $\begin{array}{l}\text { ARIMA - GARCH } \\
\text { bootstrapping }\end{array}$ \\
\hline Glisovic et al. (2016) & Neural Network & $\begin{array}{l}\text { Genetic Algorithm on } \\
\text { Neural Network }\end{array}$ \\
\hline
\end{tabular}


term planning, inventory management in tandem with revenue management structure is generally the objective of research.

Another forecasting objective closely related with short term inventory management is overbooking management. As mentioned earlier, in passenger transport, each seat unoccupied is a lost opportunity. The transport industry has taken a challenging approach to maximize revenue by keeping unoccupied seats at the lowest. Even if the seats are all booked to capacity, some fail to turn up at the time of departure ("no show"). If the no show rate could be predicted, the seats that would remain empty due to no-show could be resold beforehand (overbooking) to gain more revenue. However, the challenge is, if the passengers turn up, defying the forecast, there is a loss to the transportation agency as they have to pay out heavy compensation.

Table 4: Forecast Objectives in Different Planning Horizons

\begin{tabular}{|c|c|c|c|c|c|}
\hline Planning horizon & operational & Planning horizon & tactical & Planning horizon & strategic \\
\hline Objective & Count & Objective & Count & Objective & Count \\
\hline Inventory Management & 33 & Capacity planning & 31 & Capacity planning & 19 \\
\hline Capacity planning & 9 & Inventory Management & 8 & Economic Growth & 11 \\
\hline Overbooking/No Show & 5 & Network Design & 1 & & \\
\hline Grand Total & 47 & Grand Total & 40 & Grand Total & 30 \\
\hline
\end{tabular}

\subsubsection{Year-wise decompositions}

A. Overall Research Initiatives Industry-wise

We also tried to draw a picture of research initiative through last thirty years. Fig. 4 shows a map of research papers published in these years in each of the industry sectors - airlines, railways and bus service sectors. The sectorwise maps were further subdivided into into categories based on short term(operational), medium term(tactical) and long term(strategic) initiatives.

As we can see from Fig. 4, the airline industry is very mature and has steady flow of publications in all levels till present time whereas the number of papers have picked up in railways sector only in recent years. There is a research gap in the bus transport sector. Many parts of Europe and Asia have strong intercity bus service networks and we were surprised not to find more related research initiatives. Similarly, we found very few papers on the maritime sector and only one on ferry service [Dehghani et al. (2010)]. We 
included six papers from cruise line industry, all published in the last decade. It is noteworthy that cruise line industry, though being a scheduled passenger transportation, operationally bears resemblance with the hotel industry, and therefore has a very unique character. However not much emphasis has been given to research in this industry until the last decade.
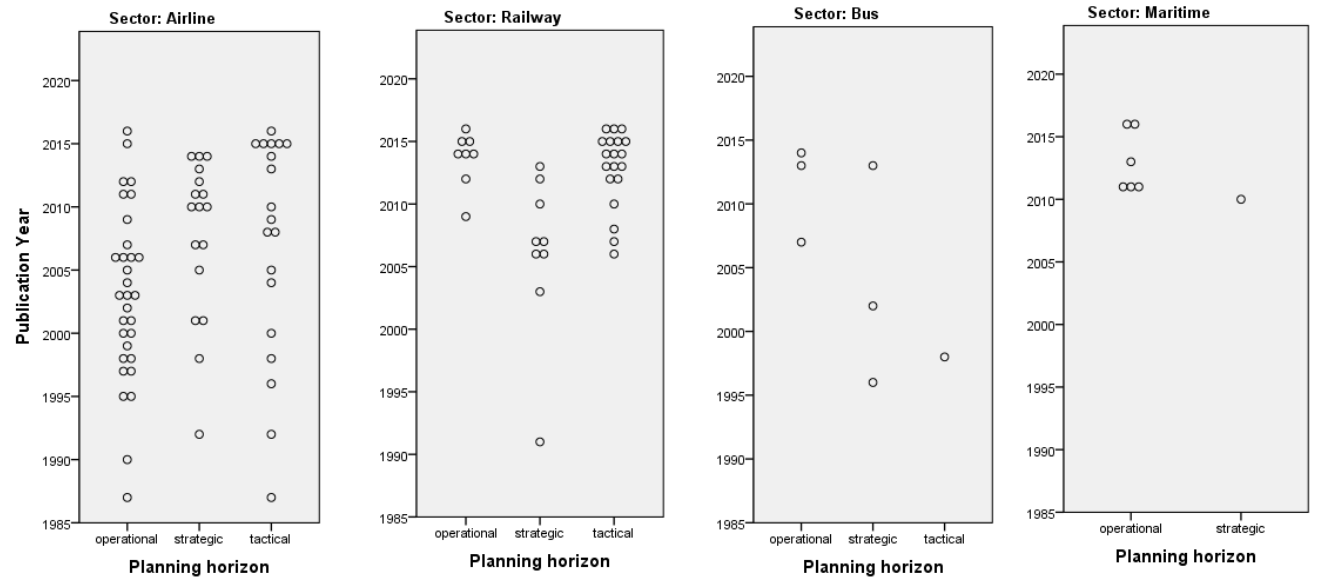

Figure 4: Sector-wise research papers in last 30 years. Each circle represents a paper.

\section{B. Overall Research Initiative Method-wise}

Mapping the usage of forecasting models during last 30 years shows the trend in forecasting. Fig. 5 depicts this usage from 1987 onward. The map does not produce any dramatic visual information, as we are expecting, perhaps due to the coarseness in classification, but we do find a spate of research activities in the last 10 years. The models that are introduced during these years are hybrid models Table (3), Grey Models, Multilayer Perceptrons, Support Vector Machine (SVM) regression and System Dynamics models.

\subsection{Forecast Models : A Technical Walkthrough}

In this section we provide an overview of the models that are shown in Fig. 2. We maintained a short introduction for each model with references which the users can look up for further reading. However the complete list of 118 research papers is also added as a supplementary material for those who want to view the full list of journal articles and other research works we have reviewed. Since it is beyond the scope to describe the models in details, 


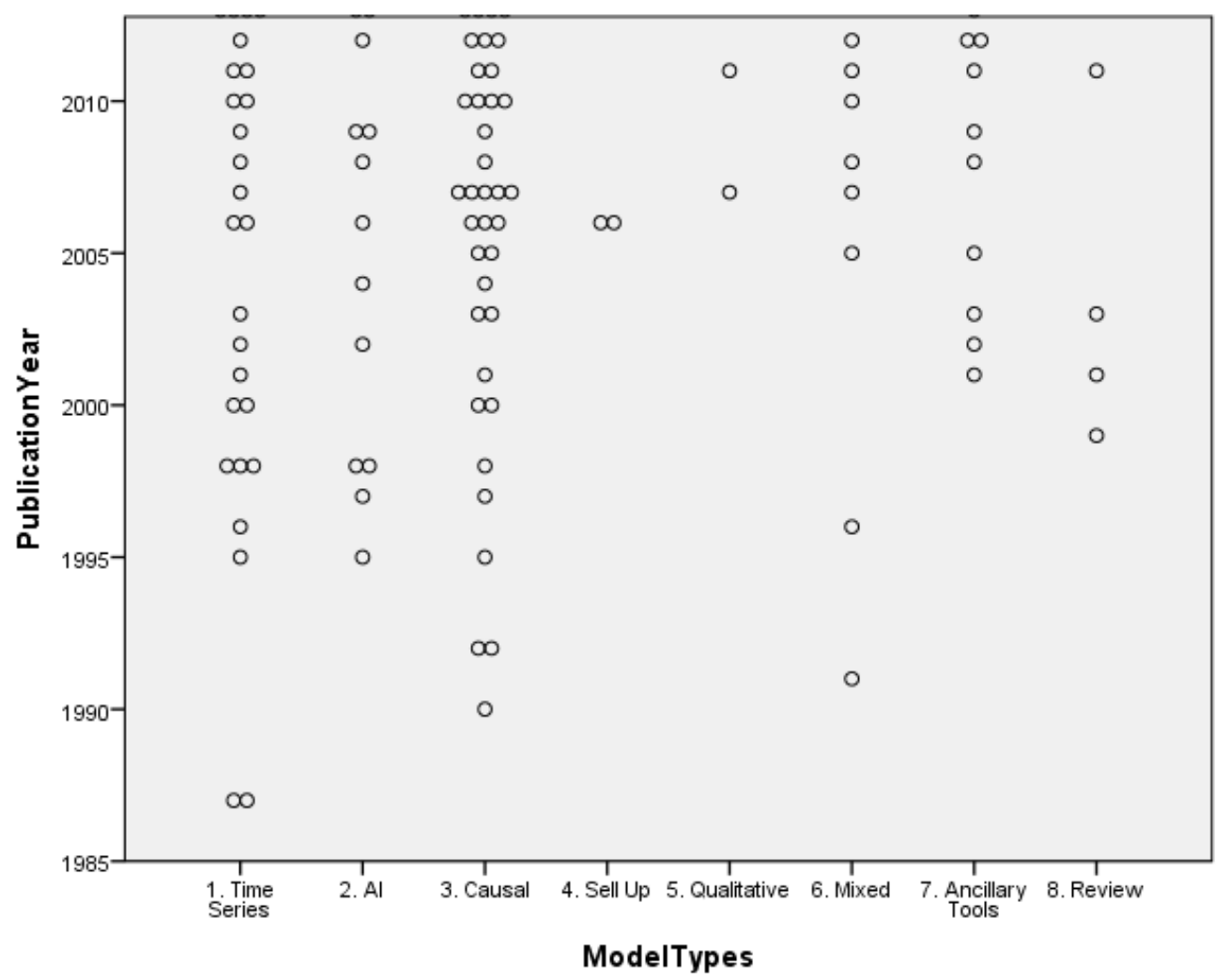

Figure 5: Usage of forecasting methods, year-wise. Each circle represents a paper.

we take the liberty of introducing the readers to few textbooks to look up. Ord and Fildes (2013) is one such book dedicated to forecasting. Talluri and Van Ryzin (2004) is more on revenue management but touches on all key forecasting models. For beginners, Hyndman and Athanasopoulos (2018) is an easy to understand book that is available online as well, and the 5 volume compendium Fildes and Allen (2011) is a suggested thorough reference.

\subsubsection{Time Series Models}

A time series model derives a forecast from a series of past observations. A univariate time series is a sequence of discrete observations taken successively at equally spaced time interval. The time series models are discussed in a compact tabular form in Tables 5 . 
Table 5: Time Series Models

\begin{tabular}{|c|c|c|}
\hline Model & Description & References \\
\hline \begin{tabular}{l}
\multicolumn{2}{l}{ Exponential } \\
Time Series \\
(ETS)
\end{tabular} & $\begin{array}{l}\text { ETS provides a forecast } \\
\text { from past data. The his- } \\
\text { torical observations are such } \\
\text { weighted that weightage of } \\
\text { the observations are de- } \\
\text { creased exponentially as the } \\
\text { data get older. }\end{array}$ & $\begin{array}{l}\text { Some examples are Samagaio and } \\
\text { Wolters (2010), Riedel and Gabrys } \\
(2003) \text {, Wickham (1995). These pa- } \\
\text { pers are comparative studies (see } \\
\text { 2). ETS is often used to benchmark } \\
\text { other models. }\end{array}$ \\
\hline $\begin{array}{ll}\text { Pickup } & \text { Fore- } \\
\text { casting } & \end{array}$ & $\begin{array}{l}\text { Pickup uses a booking ma- } \\
\text { trix. The objective is } \\
\text { to accumulate the "pickup" } \\
\text { or trend from progressive } \\
\text { booking for a scheduled } \\
\text { journey and then project } \\
\text { them into cumulative fore- } \\
\text { cast for the journey. }\end{array}$ & $\begin{array}{l}\text { Generally very effective in short } \\
\text { term forecasting, often used in } \\
\text { tandem with revenue manage- } \\
\text { ment,Wickham (1995) used this in } \\
\text { airline, Dutta and Ghosh (2012) in } \\
\text { railways, Sun et al. (2011) in cruise } \\
\text { line. }\end{array}$ \\
\hline $\begin{array}{l}\text { AR (Autore- } \\
\text { gressive) }\end{array}$ & $\begin{array}{l}\text { AR is a regression of a vari- } \\
\text { able against itself. In time } \\
\text { series forecasting, each ob- } \\
\text { servation is a regression of } \\
\text { past observations. If the im- } \\
\text { mediate historic observation } \\
\text { correlates to present obser- } \\
\text { vation the model is called } \\
\mathrm{AR}(1) \text {, If the correlation is } \\
\text { one observation apart, it is } \\
\mathrm{AR}(2) \text { and so on }\end{array}$ & $\begin{array}{l}\text { Riedel and Gabrys (2003) used } \\
\text { as a comparative analysis with } \\
\text { ARMA,ETS and other models, with } \\
\text { seasonal and market adaptation and } \\
\text { also to forecast flight specific de- } \\
\text { mands, Sickles et al. (1998) used } \\
\text { AR, MA and ARMA models for } \\
\text { identifying "strategic" demand of } \\
\text { aircraft acquisition. }\end{array}$ \\
\hline $\begin{array}{l}\text { MA (Moving } \\
\text { Average) } \\
\text { ARMA }\end{array}$ & $\begin{array}{l}\text { MA is a Regressive model } \\
\text { based on past forecast er- } \\
\text { rors. } \\
\text { ARMA is a model with au- } \\
\text { toregressive and moving av- } \\
\text { erage model combined to- } \\
\text { gether }\end{array}$ & $\begin{array}{l}\text { Riedel and Gabrys (2003) and Sick- } \\
\text { les et al. (1998), as discussed above } \\
\text { Riedel and Gabrys (2003), Sickles } \\
\text { et al. (1998) }\end{array}$ \\
\hline
\end{tabular}

Continued on next page 
Table 5 - Continued from previous page

\begin{tabular}{|c|c|c|}
\hline Model & Description & References \\
\hline $\begin{array}{l}\text { ARIMA and } \\
\text { seasonal } \\
\text { ARIMA } \\
\text { models }\end{array}$ & $\begin{array}{l}\text { AR, MA and ARMA mod- } \\
\text { els are stationary, i.e., they } \\
\text { do not incorporate trend. } \\
\text { So a differencing factor } d \\
\text { is brought in to detrend. } \\
\text { Seasonal ARIMA models, } \\
\text { also known as SARIMA, } \\
\text { takes into account seasonal- } \\
\text { ity as well. Further devel- } \\
\text { opments like X-11 ARIMA, } \\
\text { REGARIMA are alogirth- } \\
\text { mic models that takes into } \\
\text { account holidays, moving } \\
\text { holidays and exigencies like } \\
\text { strikes. }\end{array}$ & $\begin{array}{l}\text { ARIMA and seasonal ARIMA mod- } \\
\text { els, specifically Box Jenkins air- } \\
\text { line model, are extensively imple- } \\
\text { mented and often used as bench- } \\
\text { marks. Ghomi and Forghani (2016) } \\
\text { used this to compare with neural } \\
\text { network, Shitan et al. (2014) used } \\
\text { this for long term planning, that } \\
\text { is, ridership in Ampang Railways. } \\
\text { Cyprich et al. (2013), in bus in- } \\
\text { dustry, extended it Reg-ARIMA to } \\
\text { incorporate trading days and holi- } \\
\text { days, Dutta and Ghosh (2012) used } \\
\text { this in Indian Railways for revenue } \\
\text { management, Samagaio and Wolters } \\
\text { (2010) used this for comparative } \\
\text { study on Lisbon Airport transit. }\end{array}$ \\
\hline Grey Model & $\begin{array}{l}\text { Grey Model is a new time } \\
\text { series concept. The objec- } \\
\text { tive is to apply a function } \\
\text { on a set of observation to } \\
\text { transform them into mono- } \\
\text { tonically increasing set of } \\
\text { data (accumulating genera- } \\
\text { tion operation or AGO op- } \\
\text { eration) and derive a fore- } \\
\text { cast from them. The fore- } \\
\text { cast can then be reverse- } \\
\text { transformed back (Inverse } \\
\text { AGO operation) into the } \\
\text { original form. }\end{array}$ & $\begin{array}{l}\text { Wang et al. (2013) compared Grey } \\
\text { Model against elastic coefficient } \\
\text { models to forecast yearly passen- } \\
\text { ger volume, Carmona Benitez et al. } \\
\text { (2013) used damped version of the } \\
\text { model for same industry, Hsu and } \\
\text { Wen (2000) applied it to forecast } \\
\text { passenger volume to design airline } \\
\text { network. }\end{array}$ \\
\hline
\end{tabular}

Continued on next page 
Table 5 - Continued from previous page

\begin{tabular}{|l|l|l|}
\hline Model & Description & References \\
\hline GARCH & GARCH is quite related to & Nieto (2015) and Adrangi et al. \\
ARMA process but it mea- & (2001) used GARCH for long term \\
sures the conditional vari- & forecasting in airline industry, Wang \\
ance instead of conditional & (2016) used it for short term revenue \\
mean as in ARMA. Real- & management purpose in a cruise line. \\
world phenomena appear to & be heteroskedastic - they \\
& $\begin{array}{l}\text { appear to have volatile pe- } \\
\text { riods followed by calm peri- } \\
\text { ods. This is captured by the } \\
\text { GARCH model. Hence the } \\
\text { name, Generalised Autore- } \\
\text { gressive Conditional Het- } \\
\text { eroskedasticity or GARCH. }\end{array}$ & \\
\hline
\end{tabular}

\subsubsection{Causal Models}

Unlike time series models, causal models try to establish the factors that can explain past demands and then use the model to provide a forecast value. A causal model tries to build an explanatory equation which fully describes an observation as an output of one or more underlying causing factors. The causal models are given in Table 6 .

Table 6: Causal Models

\begin{tabular}{|c|c|c|}
\hline Model & Description & References \\
\hline Regression & $\begin{array}{l}\text { Regression identifies the relation- } \\
\text { ship between a scalar dependent } \\
\text { variable and one or more explana- } \\
\text { tory variables. The forecast is de- } \\
\text { rived from the dependent variable } \\
\text { when explanatory variables val- } \\
\text { ues are provided. }\end{array}$ & $\begin{array}{l}\text { Regression analysis is quite com- } \\
\text { mon in transportation forecasting } \\
\text { for both short term and long term } \\
\text { predictions. Earliest example in } \\
\text { our review study is by Sa (1987) } \\
\text { but one may look into Dutta and } \\
\text { Marodia (2015) for more explana- } \\
\text { tion on usage of regression, spe- } \\
\text { cially for revenue management. }\end{array}$ \\
\hline
\end{tabular}


Table 6 - Continued from previous page

\begin{tabular}{|c|c|c|}
\hline Model & Description & References \\
\hline Logit models & $\begin{array}{l}\text { Logit models are regression mod- } \\
\text { els where dependent variables are } \\
\text { categorical. In binomial Logit } \\
\text { models the dependent variable } \\
\text { is binary with only two val- } \\
\text { ues whereas in in multinomial } \\
\text { logit models dependent variable is } \\
\text { nominal or categorical. }\end{array}$ & $\begin{array}{l}\text { Logit models such as multino- } \\
\text { mial, nested and cross nested } \\
\text { models are extensively used to } \\
\text { forecast demand through passen- } \\
\text { ger choice modelling. As long } \\
\text { term planning examples, Liu and } \\
\text { Li (2012) used logit models to } \\
\text { model demand in intercity high } \\
\text { speed railway system, Ashiabor } \\
\text { et al. (2007) in nationwide inter- } \\
\text { city travel. Cipriani et al. (2014) } \\
\text { used logit for analysis on passen- } \\
\text { ger choice in flights between two } \\
\text { cities. In short term forecasting, } \\
\text { especially from a revenue man- } \\
\text { agement perspective, (Talluri and } \\
\text { van Ryzin, 2004) used logit to } \\
\text { model passenger choice in single } \\
\text { leg booking problem. }\end{array}$ \\
\hline $\begin{array}{l}\text { Econometric } \\
\text { models }\end{array}$ & $\begin{array}{l}\text { The econometric causal models } \\
\text { may include some form of multi- } \\
\text { nomial regressions or some other } \\
\text { relationship forms such as grav- } \\
\text { ity models. Gravity model is of- } \\
\text { ten used to identify travel inter- } \\
\text { actions between two cities or re- } \\
\text { gions. }\end{array}$ & $\begin{array}{l}\text { Leng et al. (2015) used a com- } \\
\text { plex } 4 \text { step algorithm which in- } \\
\text { cludes regression, gravity model } \\
\text { and induced demand model to } \\
\text { forecast passenger flow in high } \\
\text { speed railway, Caseetta and Cop- } \\
\text { pola (2014) derived a single util- } \\
\text { ity function equation combining } \\
\text { all the factors to forecast pas- } \\
\text { senger demand for intercity high } \\
\text { Speed Rail. Tsekeris and Tsekeris } \\
\text { (2011)'s study is an exploratory } \\
\text { overview on such models, }\end{array}$ \\
\hline
\end{tabular}

Continued on next page 
Table 6 - Continued from previous page

\begin{tabular}{|c|c|c|}
\hline Model & Description & References \\
\hline $\begin{array}{l}\text { Bayesian } \\
\text { models }\end{array}$ & $\begin{array}{l}\text { Bayesian State Space models can } \\
\text { be created by generating current } \\
\text { state matrix from observed data } \\
\text { in a time series. A state space } \\
\text { model can be represented by a } \\
\text { pair of equations called transi- } \\
\text { tion and measurement equations. } \\
\text { Transition equation provides the } \\
\text { state vector representation of the } \\
\text { system and measurement equa- } \\
\text { tion provides the relationship be- } \\
\text { tween observed time series data } \\
\text { and the state of the system. }\end{array}$ & $\begin{array}{l}\text { Jiao et al. (2016), Milenkovic } \\
\text { et al. (2013), Aston and Koopman } \\
(2006), \text { Saab and Zouein (2001) }\end{array}$ \\
\hline
\end{tabular}

\subsubsection{AI models}

Artificial Intelligence or machine learning models are computation intensive self learning algorithms. The self learning algorithms are those who rectify and fine tune the explanatory model iteratively by evaluating the result and reducing the error margin each time. Given in Table (8) are AI models.

\subsubsection{Sell Up Models for Low Cost Carrier (LCC) Airline Businesses}

There are several differences between the business models of low cost carriers and legacy carriers which motivate the different approaches which LCC carriers take to demand forecasting. In particular legacy carriers have historically marketed their product through fareclasses, and use fareclasses as a core forecasting entity. Fareclasses are products which are differentiated by price and the conditions attached to the ticket (for example conditions relating to cancellation or booking change or restrictions on return flights). LCC do not structure their product in terms of fareclasses, but nevertheless seek to price discriminate. Hence LCC carriers have developed forecasting models which explicitly model the likelihood of retaining or losing demand if a higher fare is charged. To elucidate further, for a certain scheduled departure, as time of departure approaches, the passenger's willingness to pay higher price increases. The LCC forecast models capture this inclination and exploits it to sell the next available seat at a higher price. 
Table 7: AI Models

\begin{tabular}{|c|c|c|}
\hline Model & Description & References \\
\hline Neural Network & $\begin{array}{l}\text { A neural network layer consists } \\
\text { of interconnected nodes starting } \\
\text { with input nodes and ending in } \\
\text { output. The network consists } \\
\text { of three types of layers, input, } \\
\text { hidden and output connected in } \\
\text { feed forward mechanism, in a di- } \\
\text { rected graph. The nodes in hid- } \\
\text { den layers are called perceptrons } \\
\text { and are responsible for recogniz- } \\
\text { ing patterns. The output is mea- } \\
\text { sured against the expected re- } \\
\text { sult. The errors are then prop- } \\
\text { agated backward. Each layer sees } \\
\text { the error propagated into it as a } \\
\text { black box and locally adjusts the } \\
\text { weights. This is called the back- } \\
\text { propagation method. }\end{array}$ & $\begin{array}{l}\text { Usage of neural network for long } \\
\text { term demand forecasting is quite } \\
\text { common such as Faraway and } \\
\text { Chatfield (1998), Crone (2004), } \\
\text { Srisaeng et al. (2015). How- } \\
\text { ever Tsai et al. (2009) used } \\
\text { them for short term demand fore- } \\
\text { casting. They compared two } \\
\text { advanced formulations,MTUNN } \\
\text { and PENN against a general mul- } \\
\text { tilayer perceptron model.Wei and } \\
\text { Chen (2012) used a hybrid neural } \\
\text { network model for passenger flow } \\
\text { forecasting in a rapid transit sys- } \\
\text { tem. }\end{array}$ \\
\hline SVM & $\begin{array}{l}\text { SVM is seen as a classification } \\
\text { tool, The support vector regres- } \\
\text { sion seeks to identify and opti- } \\
\text { mize the bounds of error for a re- } \\
\text { gression. The cost of error is cal- } \\
\text { culated as zero if the observation } \\
\text { falls within the bounds. This is } \\
\text { often referred to as epsilon inten- } \\
\text { sive loss function. }\end{array}$ & $\begin{array}{l}\text { Jiang et al. (2015) used Grey } \\
\text { SVM with empirical mode de- } \\
\text { composition (EMD) for passenger } \\
\text { flow forecasting in high speed rail. } \\
\text { Xie et al. (2013) performed least } \\
\text { square SVM modelling with EMD } \\
\text { for passenger flow forecasting in } \\
\text { airport terminal. }\end{array}$ \\
\hline
\end{tabular}


There are two approaches to adopt to LCC framework. The forecasting models are "Q forecasting" and "fare adjustment". Both are run on Passenger Origin Destination Simulator (PODS) developed at Boeing lab. They are discussed as below.

Table 8: Sell Up Models

\begin{tabular}{|c|c|c|}
\hline Model & Description & References \\
\hline Q Forecasting & $\begin{array}{l}\text { The aim of this process is to keep the existing fare } \\
\text { class structure of the legacy system, but to calcu- } \\
\text { late the total passengers in terms of Q class pas- } \\
\text { senger. Q class is the lowest fare class. The de- } \\
\text { mand for higher class fares are calculated based } \\
\text { on the probability that Q class passenger willing } \\
\text { to pay higher class fare when Q class fare is made } \\
\text { unavailable. }\end{array}$ & $\begin{array}{l}\text { Cooper et al. } \\
(2006), \quad \text { Reyes } \\
(2006) \text { and } \\
\text { Claz-Savoyen } \\
(2005) .\end{array}$ \\
\hline $\begin{array}{l}\text { Fare } \quad \text { Adjust- } \\
\text { ment }\end{array}$ & $\begin{array}{l}\text { This system works with a standard version of } \\
\text { network level revenue management called DAVN } \\
\text { (Displacement Adjusted Virtual Nesting) as is, in } \\
\text { essence, an optimizer. Fare adjustment lowers } \\
\text { the pseudo fare by a a certain amount known as } \\
\text { "Price Elasticity Cost". This is the lost opportu- } \\
\text { nity of sell up. By reducing the pseudo fares, these } \\
\text { fare classes are shifted into lower virtual nests and } \\
\text { therefore will be closed earlier. This will force a } \\
\text { sell up. }\end{array}$ & $\begin{array}{l}\text { Cooper et al. } \\
(2006), \quad \text { Reyes } \\
(2006) \text { and } \\
\text { Claz-Savoyen } \\
(2005) .\end{array}$ \\
\hline
\end{tabular}

\subsubsection{Qualitative Model - Expert Judgment}

Expert judgment is an import aspect in demand forecasting. Historical data is used to produce demand forecast but cannot take into account immediate market changes. It, therefore, depends on the Analyst to interpret the changes and adjust the forecast accordingly. Expertise of the analyst in reading the uncertainties is a critical factor in this kind of adjustment. Expert judgment is an important component in any kind of forecasting as lack of objective data and immediate changes in the forecasting environment (such as market trend) always add uncertainties to forecasts. Mukhopadhyay et al. 
(2007) discussed in detail, with an example, the role of expert judgement for improving forecast accuracy in revenue management

\subsubsection{Mixed Models}

These tools are mix of quantitative and qualitative methods. Qualitative methods may include customer surveys, qualitative scales for measurements while quantitative methods may also include graphs and schematic representations as well as mathematical derivations. The mixed models are tabulated in Table 9.

\subsubsection{Ancillary Tools}

\section{A. Aggregation}

Aggregation is a major concern for forecasting. While inventory or revenue management needs data at the most granular day to day level, the tactical or strategic needs might require forecasting at monthly or yearly level. So different objectives demand different levels of aggregation. However there are challenges associated with the nature of the data at different levels of hierarchy. At the most granular level, the datasets are smaller and probability of noise elements masking the characteristics of the data is more whereas at more generalised level, the special characteristics of certain parts of the data may be damped or even lost. Riedel and Gabrys (2005) expressed this problem from a practitioner's angle - at what level should we do the forecast? Can we decompose the forecasts, if needed, to a more granular level? Can we aggregate them, to more higher level? They inferred from their experiments that decomposition of forecasts to lower level perform poorly but aggregation of forecasts to higher level performs better. However they also warned multilevel forecasting may increase the number of forecasts to combine resulting in overfitting.

\section{B. Demand Unconstraining}

Booking data, as said before, does not reflect true demand as the booking stops when the booking limit is reached though the demand for the seats may not be satisfied. If this demand is not identified and the real demand is assumed to be equal to booking limit, the forecasting mechanism is bound to produce an underestimation. Lower forecast may have a negative impact on the revenue management system of the business. This type of demand data bound by the booking limit is called "censored data" and needs to be "unconstrained". Some generally accepted meaningful methods to unconstrain demand data are given as below. 
Table 9: Mixed Models

\begin{tabular}{|c|c|c|}
\hline Model & Description & References \\
\hline $\begin{array}{l}\text { Logical Analysis } \\
\text { of Data }\end{array}$ & $\begin{array}{l}\text { Logical analysis data (LAD) is a based on a } \\
\text { philosophy of inquiry which is starkly differ- } \\
\text { ent from that underpinning the statistically- } \\
\text { based quantitative forecasting methods dis- } \\
\text { cussed in section } 3.2 .1 \text {. In this approach } \\
\text { analysts identify patterns in data which are } \\
\text { unique to journeys and use these patterns to } \\
\text { build predictive theories. }\end{array}$ & $\begin{array}{l}\text { Dupuis et al. (2012) used } \\
\text { LAD to forecast no show } \\
\text { in a legacy airline. The } \\
\text { now show rate for a par- } \\
\text { ticular flight provides a } \\
\text { guidance on how much } \\
\text { overbooking can be done. }\end{array}$ \\
\hline $\begin{array}{l}\text { Stated Prefer- } \\
\text { ence }\end{array}$ & $\begin{array}{l}\text { Stated Preference is a decision analysis tool } \\
\text { to model consumer choices. Stated prefer- } \\
\text { ences play an important role in product de- } \\
\text { sign and demand forecasting for different cat- } \\
\text { egories of services. The basic steps of stated } \\
\text { preference are- (a) Survey - To identify cus- } \\
\text { tomer preferences, The questionnaire often } \\
\text { contains trade off games. (b) Utility func- } \\
\text { tion - to suggest a linear utility function that } \\
\text { can define the trade off (c) Estimation - Pre- } \\
\text { ferred option is estimated by applying utility } \\
\text { function to survey data. }\end{array}$ & $\begin{array}{l}\text { Stated preference is a } \\
\text { common way to perform } \\
\text { passenger choice mod- } \\
\text { elling. Whitaker et al. } \\
(2005) \text {, is a classic ex- } \\
\text { ample of modelling pas- } \\
\text { senger choice on a flight } \\
\text { route, Fowkes and Pre- } \\
\text { ston (1991) used it to } \\
\text { identify the likely usage } \\
\text { of a new rail system. }\end{array}$ \\
\hline $\begin{array}{l}\text { Analytical Hi- } \\
\text { erarchy Process } \\
(\mathrm{AHP})\end{array}$ & $\begin{array}{l}\text { AHP is a hierarchical multi criteria decision } \\
\text { analysis tool. The objective is to choose from } \\
\text { a set of alternatives, given a set of criteria. } \\
\text { However AHP is a theory of pairwise com- } \\
\text { parison, that is, alternatives are compared in } \\
\text { pairs and importance of each one over the } \\
\text { other is measured in absolute scale. }\end{array}$ & $\begin{array}{l}\text { Dozic and Kalic (2014) } \\
\text { used AHP for aircraft } \\
\text { type selection (capactiy } \\
\text { wise) for existing airline } \\
\text { network. }\end{array}$ \\
\hline $\begin{array}{lr}\text { System } & \text { Dy- } \\
\text { namics } & (\mathrm{SD}) \\
\text { and } & \text { Agent } \\
\text { Based Modelling } \\
(\mathrm{ABM})\end{array}$ & $\begin{array}{l}\text { SD and ABM are models to understand be- } \\
\text { haviour of a complex systems. While SD is a } \\
\text { top down modelling approach based feedback } \\
\text { between different components of the system, } \\
\text { ABM works as a bottom up approach stress- } \\
\text { ing on the set of agents in the system and the } \\
\text { interaction rules set for the agents. While } \\
\text { ABM gives a granular picture of the system, } \\
\text { computer based } 23 \mathrm{~g}^{3} \text { ent based modelling simu- } \\
\text { lation takes a long time to compute whereas } \\
\text { SD models operate at more aggregate level. }\end{array}$ & $\begin{array}{l}\text { Suryani et al. (2010) used } \\
\text { SD for estimation of de- } \\
\text { mand for airport capac- } \\
\text { ity planning. Lewe et al. } \\
\text { (2014) introduced multi- } \\
\text { paradigm approach com- } \\
\text { bining ABM and SD, for } \\
\text { transportation planning. }\end{array}$ \\
\hline
\end{tabular}


a. Direct Capture: The passenger booking system keeps taking booking request even after booking limit is reached. However the problem in this case is to arrange alternative accommodation for the customers who have requested booking after booking limit is reached.

b. Mean Imputation Method: If the data is censored, ie, booking limit is reached, that data is rejected and replaced by mean of historical data where data is not censored, i.e, booking limit is not reached. However this will induce a negative bias into the booking data.

c. Median Imputation Method: Similar to mean imputation method, but median data is taken instead of mean.

d. Percentile Imputation Method: In this case, certain demand estimate is from booking rate at certain percentile data. For example, if the booking limit is reached and booking is closed then the booking rate at 75th percentile data will be visited and the estimate for total demand will be calculated from that data. However, if demand is so high that booking needs to be closed, booking rate at $75 \%$ data will also be higher and therefore estimate will also be higher than booking limit.

e. Multiplicative Booking Profile Method: The data for a low demand journey is observed all through the booking period. Then at each phase, the percentage increase is calculated. The pattern of increase at each phase is identified and replayed on a high demand journey, (where data gets censored due to booking limit), to identify uncensored demand.

f. Expectation Maximization Method: This method is a general purpose algorithm to perform a maximum likelihood estimation for incomplete data. It has been successfully implemented in censored data, missing data and truncated information cases. This algorithm is a two step process, consisting of an estimation (E) step followed by a maximization (M) step. At E step uncensored data is manufactured for censored data set, and at $\mathrm{M}$ step the data is evaluated. The steps are repeated until the convergence condition is met.

However this is not an exhaustive list. For a list of all types of demand unconstraining methods reader may refer to Guo et al. (2012). Zeni (2001) provides a detailed discussion on some common demand unconstraining methodologies. For a practitioner, the easiest option to take, obviously, would be the direct capture method. But the method is rarely acceptable as it may lead to huge overbooking. The most common and most reliable 
method is expectation maximization method. Projection detruncation is another method, very similar to expectation maximization and is also used commonly. Among other methods that are used are Holt's double exponential method explained in Guo et al. (2012) and Kourentzes et al. (2017). Kourentzes et al. (2017) also reports better results from Croston's method if demand is intermittent.

\section{Forecast Combination}

Bates and Granger (1969) first proposed that combination of forecasts from different models produce better forecasts than the models acting individually. Combination forecasting is a quite common predictive model since then. Forecast combinations helps to reduce the uncertainties associated with individual models and increases forecast accuracy by exploiting the strengths of the models (Lemke et al., 2009). There are different methods to produce combination forecasts can be broadly classified as linear or nonlinear. Some examples of linear combination methods are - simple average of the forecasts produced by the models; the outperformance model where constituent forecasts are linearly combined but weights are assigned based on historic forecast performance; regression based combination where constituent forecasts are used as regressors; and the optimal model where weights are assigned based on covariance. De Menezes et al. (2000) has provided a practical guideline for using different linear forecast combinations based on variance, skewness and serial correlation as evaluation criteria. According to their suggestion outperformance and simple average combinations work better for small sample size while optimal and regression based combinations are better for large samples.

The nonlinear forecasting are generally multistep processes which may employ different techniques such as using a quadratic equation to fit results of multiple models or classification techniques to group the results into different categories. Table 3 provides details of research papers that worked with forecast combinations.

\section{Forecast Evaluation Techniques}

Forecast evaluation techniques are run on test datasets to identify how much the predictions deviated from the observed values. Forecast evaluation or goodness of fit tests are key elements in measuring the success or failure of forecast models. Therefore they deserve mention even if quite briefly. However forecast evaluation techniques do not measure success or failure in absolute terms but are used to compare performances of forecast models 
against each other. Some of the most common and simplest techniques are Mean Absolute Error (MAE), Mean Absolute Percentage Error (MAPE), Root Mean Square Error (RMSE), Sum of Squared Error(SSE). R Squared is also a common technique to evaluate models. $\mathrm{R}$ Squared compares the fit of the chosen model to with a horizontal straight line. In case of non stationarity in the time series, a Stationary R Squared is used. The Autocorrelation Function (ACF) and Partial Autocorrelation Function (PACF) of the residuals are often used to identify whether model has correctly explained the time series. Akaike Information Criterion (AIC) and Bayesian Information Criterion (BIC) are two other techniques used widely as goodness of fit measures. With all these techniques available, it remains to the researcher to adopt one of those to evaluate the results of forecasting. It is also common to use other econometric technique such as Theil's Inequality Coefficient for the purpose of evaluation. Papers by Wickham (1995), Usman (2003), and Fildes et al. (2011) provided detailed explanation of forecast evaluation techniques. In the context, Hyndman and Koehler (2006)'s short paper is also worth reading, a comparative study of goodness of measures. It also introduced a new technique called Mean Absolute Scaled Error (MASE). From our collection, we shortlisted all the papers which have clearly mentioned the use goodness of fit measures to evaluate their models and listed them in Table 10. RMSE, MAPE and MAE are found to be the most common choices.

However, whatever measuring technique be adopted, the model should consistently produce same results, given the same set of data. This is termed as reproducibility. Some models, however, such as Neural Networks, may tend to produce different results in each individual run but may converge to a mean over a number of runs. These are known aberrations and can easily be rectified by averaging results of multiple runs. However, in general, reproducibility means that under the same environment, results should not vary. We refer to Boylan et al. (2015), which points out that analysis techniques such as interpretation of data, application of model or usage of different software also play significant role in producing different results for the same dataset. It is therefore imperative to document and rationalise every step of analysis process. 
Table 10: Forecast Evaluation Methods Used

\begin{tabular}{|c|c|c|c|}
\hline References & Methods Uses & References & Methods Used \\
\hline $\begin{array}{l}\text { Carson et al. } \\
(2011)\end{array}$ & MAE, RMSE & $\begin{array}{l}\text { Profillidis } \\
\text { and Botzoris } \\
(2007)\end{array}$ & Thiel's \\
\hline $\begin{array}{l}\text { Faraway and } \\
\text { Chatfield } \\
\text { (1998) }\end{array}$ & SSE & $\begin{array}{l}\text { Riedel and } \\
\text { Gabrys } \\
(2003)\end{array}$ & MAE) \\
\hline $\begin{array}{l}\text { Fildes et al. } \\
(2011)\end{array}$ & $\begin{array}{l}\text { Root Mean Square } \\
\text { Percentage Error } \\
\text { (RMPSE), Geometric } \\
\text { Root Mean Square } \\
\text { Error, Mean Absolute } \\
\text { Scaled Error, Geo- } \\
\text { metric Mean Relative } \\
\text { Absolute Error. }\end{array}$ & $\begin{array}{l}\text { Samagaio } \\
\text { and Wolters } \\
(2010)\end{array}$ & RMPSE \\
\hline $\begin{array}{l}\text { Ghomi and } \\
\text { Forghani } \\
(2016)\end{array}$ & MAPE & $\begin{array}{l}\text { Srisaeng et al. } \\
(2015)\end{array}$ & $\begin{array}{l}\text { MAE, MSE, MAPE, } \\
\text { RMSE }\end{array}$ \\
\hline $\begin{array}{l}\text { Glisovic et al. } \\
(2016)\end{array}$ & $\begin{array}{l}\text { Normalised BIC, } \\
\text { MAPE, Stationary R } \\
\text { Squared }\end{array}$ & $\begin{array}{l}\text { Wickham } \\
\text { (1995) }\end{array}$ & Thiel's \\
\hline $\begin{array}{l}\text { Lemke and } \\
\text { Gabrys } \\
(2008)\end{array}$ & MSE, MAPE & $\begin{array}{l}\text { Xie et al. } \\
(2013)\end{array}$ & RMSE, MAE, MAPE \\
\hline $\begin{array}{l}\text { Ma et al. } \\
(2014 b)\end{array}$ & $\begin{array}{l}\text { SSE, MAE, RMSE, } \\
\text { MAPE }\end{array}$ & Zickus (1998) & Revenue performance \\
\hline $\begin{array}{l}\text { Milenkovic } \\
\text { et al. (2014) } \\
2014\end{array}$ & $\begin{array}{l}\text { Stationary R Squared. } \\
\text { MAPE, Normalized } \\
\text { BIC }\end{array}$ & Zong (2015) & $\begin{array}{l}\text { MAE, Mean Relative } \\
\text { Error }\end{array}$ \\
\hline
\end{tabular}

\subsubsection{Review Papers}

The review paper by McGill and Van Ryzin (1999) is worth mentioning, in the context, because of the extensive works they have done. The paper discussed forecasting research from the revenue management perspective and listed important forecasting papers during the period 1958-1999. The paper also listed papers on overbooking during the same period. Among other 
issues that are discussed are aggregating and disaggregating the forecasts and demand unconstraining. The authors also concluded on the importance of manual intervention in case of market changes. It is interesting to note that the authors expressed regret that they were unable comprehend research trends due to reluctance of airlines to share information. Twenty years on, we still find the lack of information sharing within the community, a theme which we will return to, in the conclusion.

\section{Conclusion}

\subsection{Implications for Practice}

With a multitude of forecasting techniques to choose from, the question that occurs first, is that of what method to use. There is no definitive answer considering that fact that there are many ways to approach a problem and each way has its own pros and cons, for example some methods are easier to implement, others are more accurate while some others can handle some certain real life problems better. However the research papers do provide a direction to assist the readers to take a decision on their own forecasting practice. While the corporate analysts looking for a quick solution may use the conventional methods, those who are already familiar with existing methods, may want to explore into latest research works.

a. Short term forecasting - The majority of short term forecasting is done to understand journey specific booking curves. Typically, the purpose of the forecast engine is to support the revenue management system. The most commonly used method is the Pickup model, of which the Advanced Pickup variant is concluded to be the most successful one. For those who want to set up a forecasting tool without hassle, we recommend Pickup forecasting. ETS would be our next choice in terms of complexity. In short term forecasting there is often a very short trail of historic data. In those cases ETS and Pickups are better tools for forecasting. AR, ARMA or ARIMA models need more efforts to implement but are often the choices of experienced practitioners. Among other models, Tsai et al. (2009) has shown that Neural Networks can be used successfully in short term forecasting. There are also some non conventional approaches as well, that are worth considering. Ma et al. (2014a), for example, has used a clustering algorithm to generate a booking curve forecast. Tsai (2014) has taken a very similar approach but used case based reasoning to forecast a booking curve from initial booking. The process has a 4 step algorithm, which works on the basis of a similarity 
evaluation between the current booking pattern from initial booking to the current point and the set of historical bookings with similar patterns. The new booking curve is then generated through weighted combinations of those historical booking patterns.

b. Medium and Long terms forecasting - The methodologies for these sections are numerous, specially when there is enough base of historic data to train a forecast model. Conventionally Holt Winter's method provide acceptable results for seasonal forecasting, specially with a damping parameter added. Box Jenkins airline ARIMA model is also a popular among users. Neural Network and Kalman Filters are also used with success. With advanced computational power in last two decades, several other options have opened up. Computationally intensive Neural Network models such as Multilayer Perceptrons also gained popularity among researchers in recent years. In another example, Xun et al. (2015) used Hadoop based computational architecture in particle swarm optimization (an iterative stochastic algorithm, modelled after bird flocking behaviour) prior to SVM regression. Among other newer techniques that have attracted interests from researchers are the Grey Model time series and the Fuzzy Logic time series.

However, from the aspect of real world problems, there are some more concerns that need to be addressed. They are, for instance, handling of social, cultural events such as Christmas, trading days and week days, moving holidays such as Easter. While multiple regression equations with dummy variables can be used to resolve this kind of problems, more tedious approach would be algorithms such as X-12 ARIMA or TRAMO which are more flexible in handling moving holidays.

c. Econometric forecasting - These models are used to forecast passenger demand between an origin and a destination for a scheduled service such as train service or flights. Logit models, specially nested logit models are used, often as a composite model along with other econometric models such as gravity models. These models are found to be useful in forecasting the utility of a long term infrastructure building project such as building a high speed rail network between two cities.

d. Expert Judgment in forecasting - This is another very important aspect to forecasting apart from the forecasting model itself. Statistical models cannot look beyond historical data and therefore are completely unaware of current conditions. In practice, a route analyst observes the all the extraneous factors that can affect passenger demand on a certain route and provide corrections to that demand. In our study we found two examples of such 
study. In cruise line Kollwitz and Papathanassis (2011) aptly exemplified why Delphi approach is needed to choose itineraries that attract maximum passenger demand. The other one, by Mukhopadhyay et al. (2007), explains usage of expert judgement on top of statistical forecast to include market factors. Apart from external factors, the promotion campaigns also have huge effect on demand and therefore needs to be anticipated by route analysts and has to be applied on modelled prediction. Analysts should also smoothen the singular spikes and troughs in the observation data that are fed to the models, else models may provide biased forecasts.

e. Passenger Choice Analysis - This is a fast growing field of study in passenger transportation industries and is worth mentioning. This analysis identifies the passenger preferences to build his/her itinerary when there are multiple alternatives to choose from. Identifying the passenger's preferences beforehand not only aids in forecasting but also helps the planners to design route and capacity plans centered around those preferences. Traditional method of doing the analysis is choice based modelling, as described earlier. However computation intensive pattern recognition techniques are also recently applied to build correlation matrix. For a practitioner, one good read to start with is Hess (2010).

It is worthwhile to note here that consumer behaviour has become markedly changed in the last decade. Internet boom, recession and business competitions are some of the many external factors that have made consumers more selective and prudent. Historical data therefore plays a considerably smaller role in predicting demand and newer techniques are being adopted to guide the industry to predict consumer behaviour. Romero Morales and Wang (2010) have studied using data mining techniques to identify past behaviour of passengers to predict cancellation and no-show. Game theory, such as in Isler and Imhof (2008) is increasingly being used to identify the outcome of competition between airlines in reducing seat fares. Currie and Rowley (2010) in their overview study have pointed out that Semantic Web (structured and machine readable world-wide web) may be one of the possible ways to collate external data to feed into revenue management system. For individual buyers, applying segregation techniques such as those adopted by credit scoring companies may produce insights into buying behaviour, the paper suggests. Needless to say, there are numerous open questions and therefore research opportunities in this area of study. 


\subsection{Recommendations for Research}

There are many open questions for research which we have identified in this paper, such as, how best to forecast demand including the holidays, specially the moving holidays like Chinese New Year or Ramadan, how to incorporate expert judgement in demand forecast when historical forecast cannot be relied upon due to market changes, what is the theoretical basis for combining forecasts and what combination method is the best choice.

However, we are principally concerned that overall the research initiatives are disjoint and lack smooth progress in this domain. Our major concerns are lack of organization in research documentation, incomplete evaluation with standard models and lack of standard test data. In our table of comparative study research (2), we found no two research papers have same dataset. Whereas two different studies on same dataset could provide some link between the studies, different datasets make the studies completely disjoint. There is one exception we noticed, MIT brought some leading names in Airline industry to come together and share data to build a simulator testbed (PODS). This paid off immensely as MIT labs produced brilliant thesis papers for past two decades. Unfortunately PODS is licensed solely to MIT researchers. We believe, research initiatives are seriously restricted as there remains no common ground to test new methodologies. Moreover, several research papers we studied, avoided comparison of their proposed models with conventional models.

In order to overcome the issues stated above and provide the research initiatives proper structure, we are putting forward two proposals to the research community to overcome those issues stated above.

\subsubsection{Proposal 1: Standardized dataset}

We suggest that standardized datasets be created for the sake of future researchers. Proposed models can be run on these standardized datasets and tested and benchmarked for future use. A newer model can run against those benchmarks and evaluate itself before running on new data sets. In this way new datasets also would become calibrated. We have observed that some of the research works are done by using the data made available by US Bureau of Transportation Statistics. Prepared datasets extracted from these data can be preserved and used further. US Airways data published by Box and Jenkins in 1975 is another such dataset which is used by many

researchers. To start such an initiative on a broader scale we are inviting 
all researchers to share their existing work. As a first step, we have contacted several authors whom we cited in this review papers with a request to share their datasets, but have not received any positive reply. We decided to set an example ourselves and uploaded a recent dataset (Banerjee (2017), http://dx:doi:org/10:15129/80f59eac-fffe-4397-a57e-75eaf78ea233) of almost one million customer booking transactions from a transportation company. In this context, we also believe that industry leaders also can pitch in and provide datasets, desensitized and anonymized, which will in turn support their cause by bridging the academia - industry gap.

\subsubsection{Proposal 2: Standard Template of Article}

It is evident that, in absence of a standard template, the research papers often miss some vital points that need to be reported to the user. Several papers such as Wickham (1995) or Zeni (2001) did emphasize on the importance of proper structure of a report. We have collated all those information into a checklist that can be used as a baseline for standardizing a research paper on demand forecasting. Given in the Appendix A is an example of the checklist. The checklist is self explanatory and is divided into several sections addressing to each section of a standard article. Similar research reporting checklists are available in other areas of science. CHEERS (http://www.equatornetwork.org/reporting-guidelines/cheers/) for health economics, is one such example. Checklists help in standardising the report and ensures replicability of the reported results. Reliable research publications are stepping stones to future research initiatives. Our checklist questionnaire or suggested structures are not binding but they were designed to ensure the reliability that a future researcher would ask for. We do not want to constrict the researcher's freedom by this checklist, the researchers may design their own reporting structure and merely reply to the questionnaire only. Unlike other checklists we have encountered, this is not a to-do list, but rather a set of simple questions which act as a guiding line. We do not expect all questions to be answered affirmatively, but even a negative answer to a question qualifies the paper by making it more structured and comprehensible.

To sum up, the amount of research on demand forecasting in transportation industry is huge and diverse and we are sure to witness far more research in this domain in near future. However research papers are hard to compare with each other and therefore the accumulation of knowledge is unnecessarily difficult and slow. The research community should therefore consider carefully to resolve these limitations in their future work. 
Acknowledgement. We would like to thank the three anonymous reviewers for their constructive feedback that helped us improve the presentation of the paper. 


\section{Appendices}

\subsection{Appendix A-Checklist Template}

Table 11: Checklist

\begin{tabular}{|c|c|c|}
\hline No. & Section & Recommendations \\
\hline 1 & Title & Does it clearly describe the study? \\
\hline 2 & Abstract & $\begin{array}{l}\text { Does it include summary of objective, summary of } \\
\text { dataset, forecast models used, key observation of the } \\
\text { analysis and conclusion drawn thereof? }\end{array}$ \\
\hline 3 & Introduction & $\begin{array}{l}\text { Does it include clear explanation on the background sce- } \\
\text { nario, purpose of the forecasting study and scope of the } \\
\text { study? }\end{array}$ \\
\hline 4 & Literature Review & $\begin{array}{l}\text { Does it include } \\
\text { i) An overview of the existing literature? } \\
\text { ii) An explanation on the value addition of the current } \\
\text { research to the existing research work? } \\
\text { ii) Justification and evaluation the model(s) chosen to } \\
\text { benchmark the current study? }\end{array}$ \\
\hline \multirow[t]{4}{*}{5} & Methodology & \\
\hline & a. Model Definition & $\begin{array}{l}\text { i) Are mathematical representations of proposed } \\
\text { model(s) and benchmark model(s) given. } \\
\text { ii) Are all input parameters mentioned and explained? }\end{array}$ \\
\hline & b. Data Definition & $\begin{array}{l}\text { i) Does the data description include } \\
\text { a. details of data in terms of origin, destination, network } \\
\text { types, trip(flight) schedules. } \\
\text { b. Vehicle capacity and travel classes for each trip. } \\
\text { c. Booking request details for each trip. } \\
\text { d. Volume of past records in months, years. } \\
\text { ii) Is the data aggregated in any manner for the study? } \\
\text { iii) Is the demand unconstraining technique explained? } \\
\text { iv) Is there a price elasticity effect observed on the de- } \\
\text { mand? If so, is it handled? } \\
\text { vii) Is there any combination function involved? }\end{array}$ \\
\hline & $\begin{array}{l}\text { c. Model Performance } \\
\text { Evaluation }\end{array}$ & Are model performance evaluation methods explained? \\
\hline
\end{tabular}

Continued on next page 
Table 11 - Continued from previous page

\begin{tabular}{|c|c|c|}
\hline No. & Section & Recommendations \\
\hline & d. Analytical Process & $\begin{array}{l}\text { i) Is the size (in number of observations) and periodic- } \\
\text { ity of training dataset required for forecasting process } \\
\text { mentioned? } \\
\text { ii) What is the size of look ahead prediction period (one } \\
\text { step ahead, two step, three step)? } \\
\text { iii) Will the model parameters be changed dynamically } \\
\text { or fixed for all through the study? } \\
\text { iv) Is the seasonality handled? } \\
\text { v) Are fixed date holidays handled? } \\
\text { vi) Are sliding holidays (or lunar calendar holidays) han- } \\
\text { dled? } \\
\text { vii) Are strikes, market changes and other exigencies } \\
\text { handled? } \\
\text { viii) Is there a scope for including expert judgment into } \\
\text { the analytical process? } \\
\text { ix)Is this forecast a roll forward, or with a fixed training } \\
\text { period and a fixed test period? If fixed, is it mentioned } \\
\text { how much percent of data used to train and how much } \\
\text { to test? }\end{array}$ \\
\hline \multirow[t]{4}{*}{6} & Analysis & \\
\hline & a. Report of the result & $\begin{array}{l}\text { i) Are there table(s) noting the performance of the pro- } \\
\text { posed model with benchmark at the desired level of ag- } \\
\text { gregation? } \\
\text { ii) Is there any explanatory note on the overall perfor- } \\
\text { mance of the model? } \\
\text { iii) Is there an evaluation of consistency and robustness } \\
\text { of the model, in case of unanticipated changes in ob- } \\
\text { served values? }\end{array}$ \\
\hline & $\begin{array}{l}\text { b. Forecast Accuracy } \\
\text { and Uncertainty }\end{array}$ & $\begin{array}{l}\text { i) Is the level of forecast accuracy economically viable } \\
\text { for system? } \\
\text { ii) Is there a study included on measurement of uncer- } \\
\text { tainty and prediction of confidence intervals? }\end{array}$ \\
\hline & $\begin{array}{l}\text { c. Summary of Re- } \\
\text { sults }\end{array}$ & $\begin{array}{l}\text { Is there a summary note mentioning the main points of } \\
\text { results analysis? }\end{array}$ \\
\hline
\end{tabular}

Continued on next page 
Table 11 - Continued from previous page

\begin{tabular}{|r|l|l|}
\hline No. & Section & Recommendations \\
\hline 7 & Conclusions & $\begin{array}{l}\text { i) Are key findings mentioned? } \\
\text { ii) Is the model deemed fit to integrate into the system } \\
\text { that it is designed for? }\end{array}$ \\
\hline a. Key Findings & $\begin{array}{l}\text { b. Limitations and } \\
\text { Generalizability }\end{array}$ & $\begin{array}{l}\text { i) Are the limitations of the model discussed? } \\
\text { ii) Can this model be extended to control atleast par- } \\
\text { tially, the limitations? } \\
\text { iii) Can this model be replicated for application in sim- } \\
\text { ilar industry? and other domains of industry? }\end{array}$ \\
\hline & c. Future directions & $\begin{array}{l}\text { Is it explained how current study can be further ex- } \\
\text { tended? }\end{array}$ \\
\hline
\end{tabular}




\subsection{Appendix B - Search Criteria}

TOPIC: (Airline or Transportation or Rail or Railway or Bus or Road or Ferry or Ferries or Cruise)

Excluding following pattern from TOPIC (Thermal or Wind or Electric* or Emission or Chemistry or Weather or Tax or Energy or Safety or Toll or Spatial or Migration or Climate or Weather))

Refined By: *TOPIC:* (Forecast*)

Including following *WEB OF SCIENCE CATEGORIES:*

Transportation Science Technology, Transportation,

Statistics / Probability, Operational research, Management Science,

Computer Science, Artificial Intelligence, Interdisciplinary Applications of Computer Science,

Multidisciplinary Sciences, Economics, Management, Business, Finance, Multidisciplinary Engineering, Aerospace,

Mathematics, Interdisciplinary Applications of Mathematics

Excluding following ${ }^{*} R E S E A R C H$ AREAS*

Automation control, Robotics, Mechanics, Instrumentations, Telecommunication, Other Science and Technology Topics,

Building Construction, Urban Studies, Material Science, Architecture

Imaging Science, Photographic Technology, Optics, Energy Fuels,

Environmental Sciences, Ecology, Geography, Physical Geography, Remote

Sensing, Water Resources, Geology, Physics, Agriculture, Meteorology and Atmospheric Sciences,

Public Administration, Sociology, Other Topics in Social Sciences, Mathematical Methods in Social Sciences,

Education, Educational Research, Information Science, Library Science, Public environmental Occupational Health, Government Law

Figure 6: WOS Query 


\section{References}

Adrangi, B., Chatrath, A., Raffiee, K., 2001. The demand for US air transport service: a chaos and nonlinearity investigation. Transportation Research Part E-Logistics and Transportation Review 37 (5), 337-353.

Ashiabor, S., Baik, H., Trani, A., 2007. Logit models for forecasting nationwide intercity travel demand a in the United States. Transportation Research Record 1, 1-12.

Aston, J. A. D., Koopman, S. J., 2006. A non-Gaussian generalization of the airline model for robust seasonal adjustment. Journal of Forecasting 25 (5), 325-349.

Avni, A., Burley, P., Casey, P., Cherney, J., Christiansen, L., Daly, J. S., Evans, R., Jared, D., Landgraf, G., Meier, A., Minotti, J., Post, B., Sandstedt, B., Sarmiento, R., Sillick, S., Sweet, B., Wendt, M., Winter, K., Yu, H., Mar. 2015. How to Search, Where to Search, and How to Put It All Together: Current Practices. Transportation Research Circular E-C194, 84 .

Banerjee, N., 2017. Passenger demand data for a transportation company 2014. Tech. rep., University of Strathclyde.

URL http://dx.doi.org/10.15129/80f59eac-fffe-4397-a57e75 eaf78ea233

Bates, J. M., Granger, C. W. J., 1969. The Combination of Forecasts. OR $20(4), 451$.

Boylan, J. E., Goodwin, P., Mohammadipour, M., Syntetos, A. A., 2015. Reproducibility in forecasting research. International Journal of Forecasting 31 (1), 79-90.

Carmona Benitez, R. B., Carmona Paredes, R. B., Lodewijks, G., Nabais, J. L., 2013. Damp trend Grey Model forecasting method for airline industry. Expert Systems with Applications 40 (12), 4915-4921.

Carson, R. T., Cenesizoglu, T., Parker, R., 2011. Forecasting (aggregate) demand for US commercial air travel. International Journal of Forecasting 27 (3), 923-941. 
Caseetta, E., Coppola, P., 2014. High Speed Rail (HSR) induced demand models. In: DeSousa, J. F., DeSousa, J. P., Costa, A., Farias, T., Melo, S. (Eds.), Transportation: Can We Do More with Less Resources? - 16th Meeting of the Euro Working Group on Transportation - Porto 2013. Vol. 111. Elsevier Science Bv, Amsterdam, pp. 147-156.

Cipriani, E., Crescenzi, L., Nigro, M., 2014. Behavioral models for the estimation of the air transport demand: the case study of Rome-London flight connection. In: DeSousa, J. F., DeSousa, J. P., Costa, A., Farias, T., Melo, S. (Eds.), Transportation: Can We Do More with Less Resources? - 16th Meeting of the Euro Working Group on Transportation - Porto 2013. Vol. 111. Elsevier Science Bv, Amsterdam, pp. 78-87.

Claz-Savoyen, R. L., 2005. Airline revenue management methods for less restricted fare structures. Thesis, Massachusetts Institute of Technology.

Cooper, W. L., Homem-de Mello, T., Kleywegt, A. J., 2006. Models of the spiral-down effect in revenue management. Operations Research 54 (5), 968-987.

Crone, S. F., 2004. A business forecasting competition approach to modeling artificial neural networks for time series prediction. C S R E a Press, Athens.

Currie, C. S. M., Rowley, I. T., 2010. Consumer behaviour and sales forecast accuracy: What's going on and how should revenue managers respond? Journal of Revenue and Pricing Management 9 (4), 374-376.

Cyprich, O., Konecny, V., Kilianova, K., 2013. Short-Term Passenger Demand Forecasting Using Univariate Time Series Theory. Promet-Traffic \& Transportation 25 (6), 533-541.

De Menezes, L. M., Bunn, D. W., Taylor, J. W., 2000. Review of guidelines for the use of combined forecasts. European Journal of Operational Research 120 (1), 190-204.

Dehghani, Y., Gihring, C. K., Shelton, D. S., Baker, T. B., Yarlagadda, A., Tung, R., 2010. Travel Demand Forecasting Analysis Challenges Supporting Washington State Ferries' Long-Range Plan Development. Transportation Research Record 2146, 2010 (2146), 84-91. 
Dozic, S., Kalic, M., 2014. An AHP approach to aircraft selection process. In: Benitez, F. G., Rossi, R. (Eds.), 17th Meeting of the Euro Working Group on Transportation, Ewgt2014. Vol. 3. Elsevier Science Bv, Amsterdam, pp. $165-174$.

Dupuis, C., Gamache, M., Page, J.-F., 2012. Logical analysis of data for estimating passenger show rates at Air Canada. Journal of Air Transport Management 18 (1), 78-81.

Dutta, G., Ghosh, P., 2012. A passenger revenue management system (RMS) for a National Railway in an Emerging Asian Economy. Journal of Revenue and Pricing Management 11 (5), 487-499.

Dutta, G., Marodia, D. P., 2015. Comparison of forecasting techniques in revenue management for a national railway in an emerging Asian economy. International Journal of Revenue Management 8 (2), 130.

Faraway, J., Chatfield, C., 1998. Time series forecasting with neural networks: A comparative study using the airline data. Journal of the Royal Statistical Society Series C 47, 231-250.

Fildes, R., Allen, P. (Eds.), 2011. Forecasting, 1st Edition. Sage Publications, London.

Fildes, R., Nikolopoulos, K., Crone, S. F., Syntetos, A. A., Sep. 2008. Forecasting and operational research: a review. Journal of the Operational Research Society 59 (9), 1150-1172.

Fildes, R., Wei, Y., Ismail, S., 2011. Evaluating the forecasting performance of econometric models of air passenger traffic flows using multiple error measures. International Journal of Forecasting 27 (3), 902-922.

Fowkes, T., Preston, J., 1991. Novel Approaches to Forecasting the Demand for New Local Rail Services. Transportation Research Part A - Policy and Practice 25 (4), 209-218.

Ghomi, S. F., Forghani, K., 2016. Airline passenger forecasting using neural networks and Box-Jenkins. In: Industrial Engineering (ICIE), 2016 12th International Conference on. IEEE, pp. 10-13. 
Glisovic, N., Milenkovic, M., Bojovic, N., Svadlenka, L., Avramovic, Z., 2016. A hybrid model for forecasting the volume of passenger flows on Serbian railways. Operational Research 16 (2), 271-285.

Guo, P., Xiao, B., Li, J., 2012. Unconstraining Methods in Revenue Management Systems: Research Overview and Prospects. Advances in Operations Research 2012, 1-23.

Hess, S., 2010. Theory and practice in modelling air travel choice behaviour. In: WIT Transactions on State of the Art in Science and Engineering, 1st Edition. Vol. 1. WIT Press, pp. 109-126.

Hsu, C. I., Wen, Y. H., 2000. Application of Grey theory and multiobjective programming towards airline network design. European Journal of Operational Research 127 (1), 44-68.

Hyndman, R., Athanasopoulos, G., 2018. Forecasting: Principles and Practice, 2nd Edition. Otexts.

Hyndman, R. J., Koehler, A. B., 2006. Another look at measures of forecast accuracy. International Journal of Forecasting 22 (4), 679-688.

Isler, K., Imhof, H., 2008. A game theoretic model for airline revenue management and competitive pricing. Journal of Revenue and Pricing Management; London 7 (4), 384-396.

Jiang, H., Miglionico, G., 2014. Airline network revenue management with buy-up. Optimization 63 (6), 849-865.

Jiang, X., Chen, X., Zhang, L., Zhang, R., 2015. Dynamic Demand Forecasting and Ticket Assignment for High-Speed Rail Revenue Management in China. Transportation Research Record (2475), 37-45, wOS:000363993200006.

Jiao, P., Li, R., Sun, T., Hou, Z., Ibrahim, A., 2016. Three Revised Kalman Filtering Models for Short-Term Rail Transit Passenger Flow Prediction. Mathematical Problems in Engineering, 1-10.

Kollwitz, H., Papathanassis, A., 2011. Evaluating Cruise Demand Forecasting Practices: A Delphi Approach. In: Gibson, P., Papathanassis, A., Milde, P. (Eds.), Cruise Sector Challenges. Gabler Verlag, Wiesbaden, pp. 39-55. 
Kourentzes, N., Li, D., Strauss, A. K., 2017. Unconstraining methods for revenue management systems under small demand. Journal of Revenue and Pricing Management. doi:10.1057/s41272-017-0117-x.

Lemke, C., Gabrys, B., 2008. Forecasting and Forecast Combination in Airline Revenue Management Applications.

URL http://eprints.bournemouth.ac.uk/8502/

Lemke, C., Riedel, S., Gabrys, B., 2009. Dynamic Combination of Forecasts Generated by Diversification Procedures Applied to Forecasting of Airline Cancellations. IEEE, New York.

Leng, N., Guo, G., Nie, L., Wu, X., 2015. Passenger Flow Forecasting for Chinese High Speed Rail Network. In: Chang, L., Guiran, C., Zhen, L. (Eds.), Proceedings of the 2015 International Conference on Mechatronics, Electronic, Industrial and Control Engineering. Vol. 8. Atlantis Press, Paris, pp. 675-678.

Lewe, J.-H., Hivin, L. F., Mavris, D. N., 2014. A multi-paradigm approach to system dynamics modeling of intercity transportation. Transportation Research Part E-Logistics and Transportation Review 71, 188-202.

Liu, R., Li, A., 2012. Forecasting high-speed rail ridership using a simultaneous modeling approach. Transportation Planning and Technology 35 (5), $577-590$.

Ma, M., Liu, J., Cao, J., 2014a. Short-Term Forecasting of Railway Passenger Flow Based on Clustering of Booking Curves. Mathematical Problems in Engineering, 1-8.

Ma, Z., Xing, J., Mesbah, M., Ferreira, L., 2014b. Predicting short-term bus passenger demand using a pattern hybrid approach. Transportation Research Part C - Emerging Technologies 39, 148-163.

McGill, J. I., Van Ryzin, G. J., 1999. Revenue management: Research overview and prospects. Transportation Science 33 (2), 233-256.

Milenkovic, M., Bojovic, N., Macura, D., Nuhodzic, R., 2013. Kalman filtering applied to forecasting the demand for railway passenger services. In: 16th International Conference on Transport Science ICTS 2013. Portoroz, Slovenia. 
Milenkovic, M., Bojovi, N., Gliovi, N., Nuhodi, R., 2014. Paper 193 Comparison of Sarima-Ann and Sarima-Kalman Methods for Railway Passenger Flow Forecasting. In: Second International Conference on Railway Technology: Research, Development and Maintenance. Civil-Comp Press, Stirlingshire, UK.

Mukhopadhyay, S., Samaddar, S., Colville, G., 2007. Improving revenue management decision making for airlines by evaluating analyst-adjusted passenger demand forecasts. Decision Sciences 38 (2), 309-327.

Nieto, M. R., 2015. An ARIMA GARCH Bootstrap based method for forecasting the air passenger demand. In: 35th International Symposium on Forecasting. Riverside Convention Centre, USA.

Ord, J. K., Fildes, R., 2013. Principles of Business Forecasting. SouthWestern Cengage Learning, Mason, Ohio.

Profillidis, V. A., Botzoris, G. N., 2007. A comparative analysis of performances of econometric, fuzzy and time-series models for the forecast of transport demand. In: 2007 IEEE International Conference on Fuzzy Systems, Vols 1-4. Ieee, Electron Devices Soc \& Reliability Group, New York, pp. 1-6.

Reyes, M. H. M. H., 2006. Hybrid forecasting for airline revenue management in semi-restricted fare structures. Thesis, Massachusetts Institute of Technology.

Riedel, S., Gabrys, B., 2003. Adaptive Mechanisms in an Airline Ticket Demand Forecasting System.

URL http://eprints.bournemouth.ac.uk/8533

Riedel, S., Gabrys, B., 2005. Hierarchical Multilevel Approaches of Forecast Combination. In: Fleuren, H., denHertog, D., Kort, P. (Eds.), Operations Research Proceedings 2004. Springer-Verlag Berlin, Berlin, pp. 479-486.

Romero Morales, D., Wang, J., 2010. Forecasting cancellation rates for services booking revenue management using data mining. European Journal of Operational Research 202 (2), 554-562.

Sa, J., 1987. Reservations forecasting in airline yield management. Tech. rep., Cambridge, MA: Flight Transportation Laboratory, Massachusetts 
Institute of Technology.

URL http://dspace.mit.edu/handle/1721.1/68058

Saab, S. S., Zouein, P. P., 2001. Forecasting passenger load for a fixed planning horizon. Journal of Air Transport Management 7 (6), 361-372.

Samagaio, A., Wolters, M., 2010. Comparative analysis of government forecasts for the Lisbon Airport. Journal of Air Transport Management 16 (4), 213-217.

Shitan, M., Karmokar, P. K., Lerd, N. Y., 2014. Time Series Modeling and Forecasting of Ampang Line Passenger Ridership. Pakistan Journal of Statistics 30 (3), 385-396.

Sickles, R. C., Good, D., Postert, A. K., Getachew, L., 1998. A model of world aircraft demand. Amer Soc Civil Engineers, New York.

Srisaeng, P., Baxter, G. S., Wild, G., 2015. Forecasting Demand for Low Cost Carriers in Australia Using an Artificial Neural Network Approach. Aviation 19 (2), 90-103.

Sun, X., Gauri, D. K., Webster, S., 2011. Forecasting for cruise line revenue management. Journal of Revenue and Pricing Management; London 10 (4), 306-324.

Suryani, E., Chou, S.-Y., Chen, C.-H., 2010. Air passenger demand forecasting and passenger terminal capacity expansion: A system dynamics framework. Expert Systems with Applications 37 (3), 2324-2339.

Talluri, K., van Ryzin, G., 2004. Revenue Management under a General Discrete Choice Model of Consumer Behavior. Management Science 50, $15-33$.

Talluri, K. T., Van Ryzin, G., 2004. The theory and practice of revenue management. No. 68 in International series in operations research \& management science. Kluwer Academic Publishers, Boston, Mass.

Tsai, T.-H., 2014. A self-learning advanced booking model for railway arrival forecasting. Transportation Research Part C-Emerging Technologies 39, 80-93. 
Tsai, T.-H., Lee, C.-K., Wei, C.-H., 2009. Neural network based temporal feature models for short-term railway passenger demand forecasting. Expert Systems with Applications 36 (2), 3728-3736.

Tsekeris, T., Tsekeris, C., 2011. Demand Forecasting in Transport: Overview and Modeling Advances. Economic Research-Ekonomska Istraivanja 24 (1), 82-94.

Usman, A. S., 2003. Demand forecasting accuracy in airline revenue management : analysis of practical issues with forecast error reduction. Thesis, Massachusetts Institute of Technology.

Wang, B., 2016. Research on cruise pricing strategy based on Forecast. Atlantis Press.

Wang, Y., Chen, X., Han, Y., Guo, S., 2013. Forecast of Passenger and Freight Traffic Volume Based on Elasticity Coefficient Method and Grey Model. In: Zhang, L., Wei, H., Li, Z., Zhang, Y., Li, M. (Eds.), Intelligent and Integrated Sustainable Multimodal Transportation Systems Proceedings from the 13th Cota International Conference of Transportation Professionals (cictp2013). Vol. 96. Elsevier Science Bv, Amsterdam, pp. 136-147.

Wee, B. V., Banister, D., Mar. 2016. How to Write a Literature Review Paper? Transport Reviews 36, 278-288.

Wei, Y., Chen, M.-C., 2012. Forecasting the short-term metro passenger flow with empirical mode decomposition and neural networks. Transportation Research Part C-Emerging Technologies 21 (1), 148-162.

Whitaker, B., Terzis, G., Soong, E., Yeh, W., 2005. Stated preference as a tool to evaluate airline passenger preferences and priorities. In: Airports, Airspace, and Passenger Management. Transportation Research Board Natl Research Council, Washington, pp. 55-61.

Wickham, R. R., 1995. Evaluation of forecasting techniques for short-term demand of air transportation. Tech. rep., Massachusetts Institute of Technology, Dept. of Aeronautics \& Astronautics, Flight Transportation Laboratory. 
Xie, G., Wang, S., Lai, K. K., 2013. Air passenger forecasting by using a hybrid seasonal decomposition and least squares support vector regression approach. In: Proceedings of the 59th World Statistics Congress of the International Statistical Institute, 2013. Hong Kong.

Xun, W., An, Y., Jie, R., 2015. Application of Parallel Particle Swarm Optimize Support Vector Machine Model Based on Hadoop Framework in the Analysis of Railway Passenger Flow Data in China. In: Ren, P., Li, Y., Song, H. (Eds.), Iaeds15: International Conference in Applied Engineering and Management. Vol. 46. Aidic Servizi Srl, Milano, pp. 367-372.

Yang, X. M., Wang, W., 2002. Applying fuzzy neural networks to predict bus line patronage. Amer Soc Civil Engineers, New York.

Zeni, R. H., 2001. Improved forecast accuracy in revenue management by unconstraining demand estimates from censored data. Ph.D. thesis, Rutgers, The State University of New Jersey.

Zickus, J. S., 1998. Forecasting for airline network revenue management: Revenue and competitive impacts. Tech. rep., Cambridge, Mass.: Massachusetts Institute of Technology, Dept. of Aeronautics and Astronautics, Flight Transportation Laboratory,[1998].

Zong, S., 2015. Research on the Combination Forecast Model based on the BP Neural Network. In: Si, H., Xu, P. (Eds.), Proceedings of the 2015 International Conference on Computational Science and Engineering. Vol. 17. Atlantis Press, Paris, pp. 49-53. 